\title{
WHY DOES THE PRODUCTION OF SOME LEARNERS NOT GRAMMATICALIZE?
}

\author{
Clive Perdue and Wolfgang Klein \\ Max-Planck-Institut für Psycholinguistik, Nijmegen, The Netherlands
}

In this paper we follow two beginning learners of English, Andrea and Santo, over a period of 2 years as they develop means to structure the declarative utterances they produce in various production tasks, and then we look at the following problem: In the early stages of acquisition, both learners develop a common learner variety; during these stages, we see a picture of two learner varieties developing similar regularities determined by the minimal requirements of the tasks we examine. Andrea subsequently develops further morphosyntactic means to achieve greater cohesion in his discourse. But Santo does not. Although we can identify contexts where the grammaticalization of Andrea's production allows him to go beyond the initial constraints of his variety, it is much more difficult to ascertain why Santo, faced with the same constraints in the same contexts, does not follow this path. Some lines of investigation into this problem are then suggested.

We take the view that there are a limited number of pragmatic, semantic, and phrasal (morphosyntactic) organizational principles at work in learner languages, and that their interaction determines the actual organization of a given learner variety. The kind of interaction, and hence the specific contribution of each principle, may vary as a function of source language influence and of the proficiency level of the learner. Thus, the process of acquisition ${ }^{1}$ can be viewed as the change in the interaction of these principles over time, and grammaticalization as one direction this change may (but need not) take, where the learner comes to give relatively more weight to phrasal principles.

In this paper we follow two beginners (Andrea and Santo, who share Italian as a source language and who acquired English in England) over a period of 2 years as they develop means to structure the declarative utterances they produce in narratives of personal experiences, interviews, and descriptions of future plans and in a 
film-retelling task, and then we look at the problem that is briefly set out in the following paragraph.

In the early stages of acquisition, both learners develop a common learner variety (called a basic variety in what follows; its characteristics are described later). During these stages, we see a picture of two learner varieties developing along similar lines to a similar interaction of phrasal, semantic, and discourse constraints, determined by the minimal requirements of the tasks we examine. Andrea subsequently develops further morphosyntactic means to achieve greater cohesion in his discourse. But Santo does not. Although we can identify contexts where the grammaticalization of Andrea's production allows him to go beyond the initial constraints of his variety, it is much more difficult to ascertain why Santo, faced with the same constraints in the same contexts, does not follow this path. This is the problem.

Before turning to the longitudinal profiles of these learners' productions, we give a short description of the type of data analyzed, together with some sociobiographical information for each of them.

\section{DATA AND INFORMANTS}

The data were collected during the course of the European Science Foundation's (ESF) research activity "Second Language Acquisition by Adult Immigrants" (Perdue, 1984), which consisted of a series of coordinated, comparative longitudinal studies of the acquisition of five European languages, including English. The data collection was organized in a cycle. A cycle is a series of regular encounters with a learner, during which a certain number of activities are carried out in a fixed order. The cycle ran for approximately 10 months and was repeated twice. Each learner, therefore, did the ordered activities three times. The activities analyzed in most detail here are three film-retellings (one per cycle, plus one further retelling in cycle 2 for Andrea). These are completed by extracts from conversations between informants and project researchers taken from each encounter and by two interviews recorded at an estate agent's office at the end of the third cycle of data collection. ${ }^{2}$

\section{Andrea}

Andrea was born in 1946. He received a general secondary level education in the scuola media, which included an elementary course in French. Then he studied electronics for 3 years in a technical college and qualified as an electrician. He went to England in his mid-30s and earned his living first by washing dishes in an Italian restaurant, then as a barman. After about 18 months' residence, he found work as an electrician in a small bakery, but his dissatisfaction with working conditions prompted him to apply for other jobs as an electrician or service engineer, and he eventually found one in another bakery.

When first interviewed (one year after arrival), he had just abandoned the language classes he had been sporadically attending three times per week; pressures of work had put an end to this. He attended no more classes in English but attempted to learn more English by reading technical journals. His contacts with English speak- 
ers were mainly instrumental: companies where he applied for jobs, estate and travel agents, doctors and dentists, and the administration that goes with owning a car. His opportunities for social interaction were very limited, as he himself said.

Despite his part-time attendance at language classes, Andrea was still a beginner when he started the project. He was a reserved and cautious learner, but he made considerable progress during the investigation. He used project encounters as a pedagogic opportunity, particularly to develop his lexicon. The overall impression at the end of cycle 3 is of a learner with adequate syntax and quite a rich lexicon, but far from native speaker competence. Unlike Santo and other Italian informants studied, he does not attempt to take control of the conversation in the project encounters.

\section{Santo}

Santo was born in 1958 in Naples, where he completed his scuola media education, which included an elementary course in English. He then obtained a professional qualification as a chef. He went to England in January 1983 for work and also to join his Italian girlfriend, who was studying there, expecting to stay indefinitely. His first project encounter took place 7 months later. At that time, he was renting a room in a house shared by people of various nationalities, including an Irish friend with whom he occasionally spoke English. He was working in an Italian restaurant and during the course of the project was promoted to first cook. Between his work and girlfriend, Santo spoke mainly Italian. His English contacts outside the project were, like Andrea's, bureaucratic encounters, often having to do with the purchase, registration, and sale of old cars and motorcycles.

Like Andrea, Santo was a beginner at the outset of data collection. He was described as a "risk-taker" at the initial screening. At the end of the study, he gave the impression of a certain fluency in his use of a rather simple English. He attended no classes in England.

In the following section we will attempt to make the general impression of Andrea's and Santo's production somewhat more precise.

\section{TOWARD A BASIC VARIETY}

In the earliest encounters, the utterance structures of both informants are very simple. In terms of Klein and Perdue (1992), they vary from nominal utterance organization to verbal utterance organization; that is, they are at the transition from clauses that consist mainly of simple noun phrases (NPs) and adjectives/adverbials to elementary verb-argument structures. There are no finite constructions (except for some formulaic expressions and some erratic attempts of Andrea; see later), and there is no case marking. If there is a verb, it occurs in a "base" form, usually the stem. There are in addition a very small number of V-ing forms. The copula is very rare.

At this early stage there appears some striking morphosyntactic variation in Andrea's production. One has the impression that his language course had empha- 
(A) NP1 - V - (NP2) - (NP3)

(B) NP1 - copula - Adip NP2 
ents are animate (Silverstein, 1976) is reflected in this data set-the controller is human in most cases (but because the other NP referents can also be human, this arrangement is more than simply "human referents first"). The constraint can be illustrated from Santo's first retelling (the controller is italicized in the examples):

\section{(1)a. the police taking away Charlie Chaplin \\ b. manager the shop speak the police \\ c. the police drive the car \\ d. Chaplin have the bread}

In utterance pattern (B), the copula is not systematically present (see below, examples (2)a and (2)b after because), but we may say that the other constituents are organized around the copula "position" as a function of their belonging to the topic or to the focus constituent of the utterance. The general constraint is

\section{(P) Focus last.}

(P) also constrains the place of the adverbial in relation to the rest of the utterance. Adverbials in focus are placed in utterance-final position, utterance-initial position being reserved for adverbials in topic. ${ }^{3}$

NP1 in pattern (B) is almost always left implicit where the "corresponding" target language (TL) position would contain it; in anaphoric, cataphoric, and deictic uses:

(2)a. _ is good because I no translator

(Andrea, 1st conversation)

b.___ is alright because now___ very hot

(Santo, 1st conversation)

(Implicit NP1s are also found in contexts where reference to a human argument of the verb is maintained; this zero anaphor is discussed later.)

A third declarative pattern:

(C) V-NP2

is also attested. Andrea uses it with the verb come back (=TL 'arrive'), corresponding perhaps to Italian usage with verbs conjugated with essere ('to be'). NP2 is postverbal because it is part of the focus constituent of the utterance; in other words, (P) constrains constituent order in pattern (C). The pattern is, however, rare in Andrea's production and completely disappears at the beginning of the second cycle of data collection. Santo, on the other hand, uses pattern (C) throughout the whole period of observation and with dynamic and stative verbs, essentially have in the latter case: have the one family ('there is/was a family'). About $10 \%$ of his declarative utterances are so structured. This is a first noteworthy difference between these two learners' production. 


\section{Verbal Morphology}

For the basic variety, the verbs of patterns (A) and (C) show no systematic morphological oppositions. In narrative sequences, the rule for both learners is that the base form is used in plot-line utterances. Andrea goes on to develop an opposition V versus $\mathrm{V}$-ing, the latter form being used to assign an action to the background of a narrative. He also ends up with a base versus simple past opposition, the latter used deictically in conversation and personal narratives and to indicate anteriority in retellings. This opposition is found for TL irregular and regular verbs (e.g., found, finished), and there is one overgeneralized regular form: taked.

Santo develops past tense marking, but only for TL irregular verbs; that is, he never uses a form like finished. In addition, he uses V-ing, but its use is randomthere seems to be no context where its use contrasts aspectually (or otherwise) with the base form.

A second noteworthy difference between these two learners is then that Andrea's verb morphology is more TL-like than Santo's at the end of the observation period.

\section{Form and Function of Noun Phrases}

Both learners rapidly set up a basic system of nominal reference: the/this $+\mathrm{N}$ for definites, one $+\mathrm{N}$ for countable indefinites, and $\mathrm{N}$ for uncountable indefinites.

Both use the pronouns $I$ and you from the beginning of the observation period.

(3)a. Target Language Researcher (TLR): Do you watch television much? Andrea: 1 no see every day (1st conversation)

b. Santo:

I lift (1 take the lift'; 1st conversation)

Third-person pronouns, however, develop much more slowly. ${ }^{4}$ This can best be illustrated by looking at Andrea's developmental sequence for reference maintenance in the film-retellings, in comparison with that of Santo. For Andrea, reference to humans is maintained in the following contexts (with examples taken from the beginning of cycle 2):

(i) By an NP of identical form (e.g., this woman... this woman):

the blonde friend tell other woman... and other woman call the emergency.

(ii) By zero anaphor (O), in the restricted conditions:

a. NP1 - V1 - X - to/for - O - V2 - X

that woman knock very strong the door for $O$ open or break the door

b. NP1 - V1 - X - (and) - $0-V 2-X$

the blonde girl help that woman and $O$ explain to the police

(iii) By pronouns:

other woman call the emergency but she can't to explain 


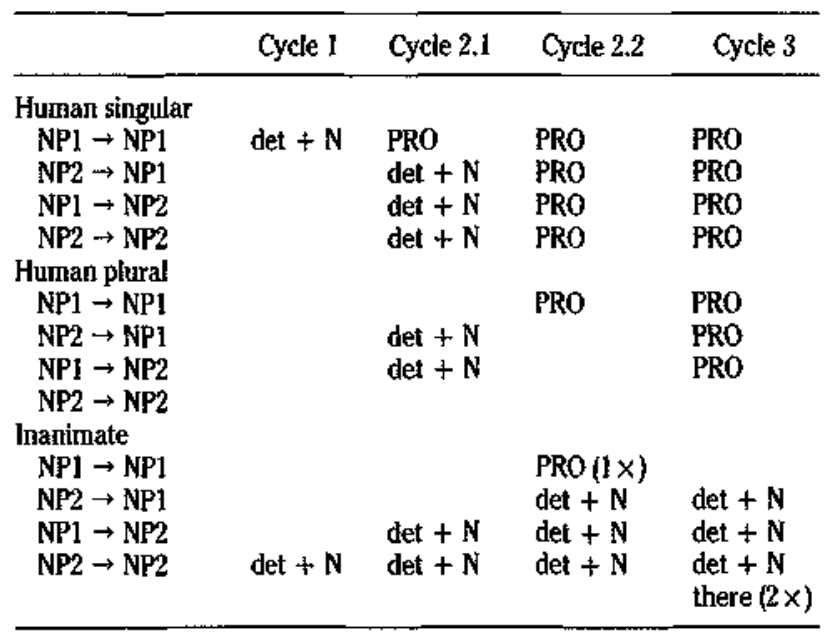


The development of third-person pronouns is a third notable difference between Andrea and Santo.

\section{Subordination}

Both learners soon use temporal, causal, and purpose phrases introduced by when, during (or between in Santo's case), because, and for (see examples 2 and, later, 5). ${ }^{5}$

The Italian connectors che and $d e$ ('that,' 'to') introducing relatives and infinitives are also found early on. In Andrea's but not Santo's production, these are gradually replaced with that and to. Relatives are infrequent and can be expressed by Santo by a "chaining" device of the form NP - V - NP - V - NP, where the middle NP (the young girl in example 4) is an argument of both verbs:

(4) this customer is the young girl take before the bread

(Santo, film-retelling, cycle 3)

Purpose clauses are more frequent. From very early on, Andrea uses embryonic infinitive constructions introduced by for (embryonic in the sense that the lexical item is vague between $\mathrm{N}$ and $\mathrm{V}$, which is one reason for having categorized them under NP3 in pattern (A) earlier):

(5) the woman phone the brigade fire for help

another woman help for ring ('telephone')

(Andrea, 1st retelling)

Next, the prepositional object complexifies - for example, for open or break the door (second retelling). For purpose clauses then give way to to purpose clauses until Andrea perceives and reuses the V-ing form, whereupon for is used again and the system scrambles, with the for subordinates followed by $\mathrm{V}$ or $\mathrm{V}$-ing, and with to losing ground.

By the third cycle, the morphological co-occurrences have been worked out: to takes over from for again and is followed by $\mathrm{V}$; with and after are followed by V-ing: with them walking on one road (fourth retelling). Andrea's development of subordination can best be described as a process of embedding. The major constituents of pattern (A) are built up; then that pattern's NP or prepositional phrase (PP) constituents complexify in turn, acquiring their own constituents, and this complexification is grammatically marked.

Santo's development is less apparent. The chaining construction (example (4) above) is maintained, and the equivalents to the TL infinitive clauses are marked indifferently by for $+\mathrm{V}$, for $+\mathrm{V}$-ing, rather than by to. This is the fourth noteworthy difference between these two learners' development.

\section{Intrinsic Factors Pushing Development}

The development beyond the basic variety in Andrea's production can be characterized, broadly speaking, as one where local markers come to carry more functional weight as he overcomes the communicative constraints of the basic variety. This 
can best be illustrated by looking at how he organizes some aspects of narrative discourse.

Initially, referents are introduced into his discourse by a lexical NP, whose determiner (this, the, one, other) depends on the possibility of associative reference (a house...the window; see Hawkins, 1983). The controller principle (S) overrides pragmatic considerations such as "mutually known" versus "new" referent. NPs occur where their semantic role property places them. This constraint weakens progressively during Andrea's development. In the narrative discourse of cycle 1, NPs referring to human entities occur only in NP1 positions; in cycle 2.1, humans are sometimes referred to by postverbal NPs as well. By the end of cycle 2, all characters (and ensembles of characters) occur freely in all positions, and inanimate referents occur (but rarely) in NP1.

This development can be put into correspondence with the discourse functions of the patterns of the basic variety (utterance patterns (A), (B), and (C) of the preceding paragraph on the basic variety). Andrea builds up a very regular variety during the course of cycle 1 . At the beginning of cycle 2, pattern (A) utterances are used only in the story line, and pattern (B) utterances provide descriptions and evaluations. In particular, pattern (B) provides one means of escaping from the principle of natural order (PNO: "recount the events in the order they occurred"6), by providing the description of a state resulting from a previous action. Other means of escape from PNO are provided by the various subordinators, but Andrea's subordination system is also being built up during the first cycle of observation, and these means only become systematic late in cycle 2, as we saw with the evolution of the distribution of V-ing, for example.

Andrea's narratives are organized up to the beginning of cycle 2 in what may grossly be termed episodes. He strings pattern (A) utterances together with and during the space/time of an episode. A new episode is marked by a coalition of features-some or all of the following: absence of utterance-initial and; presence of an utterance-initial time adverbial; full lexical NP in NP1 of pattern (A), or, much less often, in NP2 of a pattern (C) utterance:

(6) after + come back the brigade fire ('then, the fire brigade arrived') (retelling, cycle 1)

That is, Andrea organizes the retelling into sequences of actions performed successively by one protagonist - the controller. The controller is in NP1, and it is in this context that economical maintenance devices occur (including 0 anaphor, cf. example (ii)b in the preceding section on form and function of NPs).

However, episodes are not a cohesive way of organizing a whole narrative, because such organization normally necessitates a resetting of the time, action, and character frames at each boundary.

How does a learner overcome the triple constraint of episode organization: contrastive use of patterns, PNO, choice of a central protagonist? Andrea's answer is the following: By acquiring morphological oppositions on V, Andrea can use pattern (A) utterances in contexts other than plot-line events, and by acquiring explicit 
reference-maintaining devices outside the NP1 --> NP1 configuration, he can keep a protagonist topical when this protagonist is not the controller of the action. These are possible internal motivations for Andrea's development. In their discussion of language history, Bates and MacWhinney (1989) envisage "a situation of competition in which semantic and pragmatic roles struggle for control over important grammatical options" (p. 21). To paraphrase these authors, we have seen here how Andrea was pushed to acquire grammatical options in order to express competing semantic and pragmatic roles more cohesively.

As we have seen, Andrea develops a functional morphology. Santo, however, does not: He perfects a contrastive use of patterns, which will be illustrated by a short extract:

(7) have the one young girl +

(8) and take in the window in the shop the bread

(9) and go away

(Santo, retelling cycle 3)

In the absence of third-person pronouns, reference maintenance is achieved by 0 anaphor and full NP; therefore, Santo can introduce a referent with (the) one $+\mathrm{N}$ in a pattern (C) utterance, as in example (7), and maintain reference to it by 0 in NP1 position in pattern (A) (examples (8) and (9)). If there is a controller (as in example (8)), it is in the topic constituent of the pattern (A) utterance and 0 unambiguously maintains reference. The referent introduced in the pattern $(C)$ utterance may be contextualized from previous discourse, either temporally or, as in example (10), spatially:

(10) behind this door is the river

(Santo, retelling cycle 3)

Careful choice of the patterns and of the form of the NP, and an appropriate use of text deixis, allow Santo to avoid "trouble" in specifying who is who. Over the three cycles, we see no major morphosyntactic development but, rather, minor adjustments to existing patterns and their constituents, which allow Santo to narrate more fluently. He becomes a virtuoso of the one-stringed violin. ${ }^{7}$

\section{Summary}

Andrea develops markedly over the observation period; Santo develops less. Early in Andrea's and Santo's first cycle, one observes a stage of relative variability. Both state that speaking in English is difficult, both rely heavily on TLR (target language researcher) scaffolding to express themselves. By the beginning of cycle 2, both have built up a remarkably similar basic learner variety in which major constituents of utterances are organized in accordance with the constraints $(\mathrm{S})$ and $(\mathrm{P})$. Then Andrea further grammaticalizes his production; that is, morphosyntactic markers come to carry greater weight in his learner variety. We have examined (a) his 
abandoning the nonstandard pattern (C), (b) his developing systematic morphological oppositions on the verb, (c) his developing case and number markings for thirdperson pronouns, and (d) his developing TL-like subordinate clauses. For Santo, it is difficult to point to clear cases of development beyond the beginning of cycle 2 .

\section{DISCUSSION}

We have followed the steps of two learners who progressed more or less successfully along a continuous developmental path, and their relative success seemingly cannot be attributed to a purely linguistic explanation. The learners build up a similar basic variety, in which the communicative constraints are the same; furthermore, they share the same source language.

Current explanations for the existence of different levels of stabilization in adult learners appeal to other factors-be they psychological, social, or even biological. Research appealing to this latter type of factor (the critical period) is typically interested in the binary phenomenon of nativelike mastery or nonmastery of (specified aspects of) the TL. The type of individual variation described here is therefore apparently not interesting for such research. Less speculative work summarized in Long (1990) points to the conclusion that age-related loss in ability is cumulative; but here Santo has youth on his side, and his acquisition nevertheless halts at a less advanced level than Andrea's.

Research appealing to social or psychological factors has traditionally sought to associate an overall level of language proficiency with a bundle of personal characteristics. Thus, the main thrust of this research has been cross-sectional. In relation to the sociobiographical information given at the beginning of this article, we find the following:

1. Length of stay does not seem, in itself, to explain the developmental differences observed. Although Santo's observation ended after 26 months of residence, as opposed to 32 months for Andrea, Santo's acquisition halted well before the end of this period.

2. Language courses do not seem to have played any decisive role. Santo was no more proficient than Andrea at the outset despite his English lessons at school, ${ }^{8}$ and Andrea's production grammaticalized in a systematic way long after the end of the few courses he was able to attend.

3. There is no remarkable difference in their exposure to the TL, if their remarks about their lack of contact with English speakers outside bureaucratic encounters are to be believed.

We are faced with that essential and elusive component of a theory of adult language acquisition-motivation. There must be some motivation for adults to apply their sophisticated language-processing capacities to the input from a new linguistic environment in the first place (Klein, 1990), and some motivation to go beyond a basic level of communicative proficiency toward a more TL-like production (as Corder pointed out in 1967).

One way of posing the problem of motivation (i.e., of integrating personal charac- 
teristics such as needs and attitudes into a dynamic, longitudinal perspective) may be to attempt ${ }^{9}$ to associate the learner's longitudinal development with (aspects of) his communicative style.

Andrea was described after his initial interview as a learner who used reactive strategies, elaborating on TLR initiatives and, thus, taking the time to plan his utterances, whereas the opposite was true for the risk-taker Santo. ${ }^{10}$ These initial and cursory descriptions were fleshed out in some detail by Roberts and Simonot (1987), who characterized "the way in which A[ndrea]'s and S[anto]'s strategies create a particular type of encounter and so a particular type of learning environment for themselves" (p. 139). These researchers compared recordings of conversations with TLRs and of interviews where the informants had been asked to make inquiries about houses available for sale at an estate agent's office. In both situations, Andrea waited for information to be demanded rather than offering it himself, offered no topics himself, and was very receptive to native speakers' reformulations of his utterances. With the estate agent, Santo was very skillful at asking questions that elicited expert information, and he was free with his personal comments on the information provided. With the TLRs, Santo clearly holds the floor, with his interlocutors mainly supplying appropriate feedback: "His utterances are marked by many of the features of unplanned discourse_He relies heavily on universal discourse principles such as: things happen in the sequence in which they are told___ He also code switches freely into Italian for many connectives, discourse markers..." (Roberts \& Simonot, 1987, p. 146).

Roberts and Simonot (1987) describe the general characteristics of the learning environment that Andrea and Santo create in spoken interaction in the TL, where Andrea is clearly more receptive to the linguistic environment than Santo. Can this insight be translated into particular contexts? Andrea's receptivity to TL input has already been evidenced by his keen, if temporary and haphazard, interest in TL agreement phenomena just after his language course. Two areas where Andrea's production subsequently grammaticalized were in the development of some verbal morphology and in his mastery of the third-person pronoun system. Santo, on the other hand, did not develop verbal oppositions, used utterance pattern (C) throughout the observation period for referent introduction, and did not end up with the TL's third-person pronoun system. Rather, 0 anaphor was used in NP1 of patterns (A) and (B) for reference maintenance.

At the outset, third-person pronouns were virtually absent from the production of both learners. A small difference can, however, be noted between these learners' responses to TL speakers' initiatives: As shown in example (11)a, Santo does not repeat pronouns, just as he does not repeat other items absent from his spontaneous production, such as the verb go in example (11)b:

(11)a. TLR: You say they live together in the house? Santo: yeah__ live together in the house

b. TLR: Why did the woman go to prison?

Santo: the woman prison because the woman no pay the bread 
(Note the full reference-maintaining NP in example (11)b.) Andrea, on the other hand, does take up such items in his responses to the TLR. Third-person anaphoric pronouns can occur in this context, as the following examples illustrate. As far as verb morphology is concerned, Andrea's early responses are variable, some being grammatical, such as

(12) TLR: Do you know where he's going?

Andrea: he's going on the kitchen window

and others being ungrammatical, from the TL point of view, such as

(13) TLR: Where has she gone?

Andrea: where she $g o$ ?

When Santo takes up verbs from the TLR's speech, their form is, however, never of the type shown in example (12) but, rather, of that in example (13). Apparently, Andrea does pay more attention than Santo to the form of such input.

\section{CONCLUSION}

For a learner who wants to be understood, the basic variety described here (and elsewhere for other types of discourse [see the concluding chapter of Klein \& Perdue, 1992]) offers a number of advantages. It is simple in structure, easy to acquire, natural to handle, and adequate for the job. It is, therefore, not surprising that second language learners build up such a system and often maintain it. Why do second language learners then go beyond this system? Two reasons have been suggested here for Andrea, the learner who does: the communicative limitations of the basic variety and becoming more TL-like. We obviously cannot weigh the influence of these factors here. Nor can we propose a theory of differential success in adult language acquisition. Rather, we point to the continuing need to embed careful linguistic descriptions of the acquisition process in the type of language use that pushed it.

\section{NOTES}

1. We are concerned here with adults who acquire a language in everyday communication with its speakers ("spontaneous" second language acquisition), namely, in circumstances where language tuition plays no role, or a negligible one, in the acquisition process. The picture may be very different for learners who receive regular language (grammar!) teaching.

2. For a detailed description of the film-retelling technique, see Klein and Perdue (1992, chap. 1.3). For details of the conversational extracts, see Bhardwaj, Dietrich, and Noyau (1988). The estate agent interviews are analyzed in detail from a sociolinguistic perspective in Roberts and Simonot (1987). Huebner (1988) gives a very detailed picture of the developmental characteristics of Santo. Readers interested in the transcripts of the data analyzed here can obtain them from the European Science Foundation Second Language Data Bank, c/o Helmut Feldweg, Max-Planck-Institut für Psycholinguistik, Wundtlaan 1, NL-6525 XD Nijmegen, The Netherlands. This is also the authors' address for correspondence. 
3. Readers interested in the detail of the theoretical framework whence the descriptive categories controller, topic, and focus are drawn, may consult von Stutterheim and Klein (1989) and Klein and Perdue (1992). For present purposes, however, it is sufficient to notice that semantic and discourse constraints on syntactic frames may be defined in these terms.

4. This by now well-attested fact demonstrates incidentally that the acquisition of subject pronouns cannot be a process that is essentially controlled by syntactic factors. Syntactically, all such pronouns are the same; functionally, they are not. It turns out that Andrea ends up virtually mastering the subject pronoun system of English, whereas Santo does not. The fact that Santo gets less far along a similar developmental path, and that the difference in progress only concerns third-person pronouns, adds further weight to the previous remark.

5. These phrases do not necessarily contain a verb at the beginning of the observation period.

6. For SLA see, among others, von Stutterheim (1986) and Bhardwaj et al. (1988).

7. For another virtuoso performance (in synchrony), see SP-22's production described in Klein (1981).

8. A reviewer suggests that Andrea's study of a third language—French—at school should be taken into account because "it is a well-established fact that multilingualism is linked with metalinguistic awareness." It may well be that this fact contributes to the adult Andrea's attitude to SLA, but the contribution can only be indirect in that this teaching was some 20 years behind him, and he maintained he had forgotten everything he had ever known about French. It should not be forgotten that both learners had received foreign language teaching at school, an experience that is deemed to awaken some degree of metalinguistic awareness in the recipient.

9. The modal is important. We are suggesting a possible way of exploring connections between motivation and linguistic development, which is not the same thing as postulating a causal link between motivation, communicative style, and acquisitional success. Such a link would have to be proved empirically.

10. These assessments did not come from the authors but, rather, from members of the British team of the European Science Foundation project who had considerable practical experience in the National Council for Industrial Language Training with foreign workers' different ways of speaking.

\section{REFERENCES}

Bates. E., 4 MacWhinney, B. (1989). Functionalist« and the competition model. In B. MacWhinney 4 E. Bates (Eds.), The crosslinguistic study of sentence processing (pp. 3-73). Cambridge: Cambridge University Press.

Bhardwaj. M. Dietrich, R., \& Noyau, C. (Eds.). (1988). Temporality (Vol. 5 of the Final Report to the ESF). Strasbourg: European Science Foundation.

Corder. S. P. (1967). The significance of learners' errors. International Review of Applied Linguistics, 5,162169.

Hawkins. J. (1983). Word order universals. New York: Academic.

Huebner. T. (1988). Italian-English: Santo. In W. Klein 4 C. Perdue (Eds.), Utterance structure (Vol. 6 of the Final Report to the ESF, pp. 87-109). Strasbourg: European Science Foundation.

Klein, W. (1981). Knowing a language and knowing to communicate. Tilburg Studies in Language and Literature, l. 75-95.

Klein, W. (1990). A theory of language acquisition is not so easy. Studies in Second Language Acquisition, 12. 219-231.

Klein. W.. 4 Perdue. C. (1992). Utterance structure: Developing grammars again. Amsterdam: Benjamins.

Long. M. (1990). Maturational constraints on language development. Studies in Second Language Acquisition, 12.251-286.

Perdue. C. (Ed.). (1984). Second language acquisition by adult immigrants: A field manual. Rowley, MA: Newbury House.

Roberts, C. \& Simonot. M. (1987). 'This is my life': How language acquisition is interactionally accomplished. In R. Ellis (Ed.). Second language acquisition in context (pp. 133-147). New York: Prentice Hall International.

Silverstein, M. (1976). Hierarchy of features and ergativity. In R. M. W. Dixon (Ed.), Grammatical categories in Australian languages (pp. 112-171). Canberra: Australian institute of Aboriginal Studies.

von Stutterheim, C. (1986). Temporalität in der Zweitsprache: Eine Untersuchung zum Erwerb des Deutschen durch Türkische Gastarbeiter. Berlin: de Gruyter.

von Stutterheim. C. 4 Klein, W. (1989). Referential movement in descriptive and narrative discourse. In R. Dietrich 4 C. Graumann (Eds). Language processing in a social context (pp. 39-76). Amsterdam: Elsevier North-Holland 